\title{
Impact of urban heat island on regional atmospheric pollution
}

\author{
C. Sarrat ${ }^{\mathrm{a}, *}$, A. Lemonsu ${ }^{\mathrm{b}}$, V. Masson ${ }^{\mathrm{a}}$, D. Guedalia ${ }^{\mathrm{c}}$ \\ ${ }^{a}$ CNRM-GAME Météo-France 42, avenue Coriolis, 31057 Toulouse cedex, France \\ ${ }^{\mathrm{b}}$ Environment Canada, Meteorological Service of Canada, Meteorological Research Branch, Dorval QC, Canada \\ ${ }^{\mathrm{c}}$ Laboratoire d'Aérologie, Université Toulouse 3, CNRS, Toulouse, France
}

\begin{abstract}
The purpose of this work is to study the impact of an urban land cover on local meteorology and spatial distribution of atmospheric pollutants over the Paris region. One anticyclonic episode from the ESQUIF campaign was simulated using the meso-scale meteorological and chemical Meso-NHC model coupled to the town energy balance (TEB) urban canopy model. A control simulation was also performed without implementing TEB in order to quantify the effect of the urban parameterization. Both meteorological and chemical model outputs were evaluated against the data collected during the experiment and most of the results are improved when TEB is applied. The simulation indicates the formation of an urban heat island (UHI) over Paris which is stronger at night than during day. The structure of the atmospheric boundary layer is also strongly influenced by the city. The present study shows that both nocturnal and diurnal urban effects have an important impact on the primary and secondary regional pollutants, more specifically the ozone and the nitrogen oxide $\left(\mathrm{NO}_{x}\right)$. The spatial distribution and the availability of pollutants are significantly modified by the urbanized area mainly due to enhanced turbulence.
\end{abstract}

Keywords: Regional atmospheric pollution; Urban area micrometeorology; Urban heat island; Urban boundary layer

\section{Introduction}

Due to growing urbanization and pollutant emissions, it was emphasized by Crutzen (2004) that, 'it will be important to explore the consequences of combined urban heat and pollution island effects for meso-scale dynamics and chemistry'. More precisely, it becomes a priority to understand the strong interactions between urban micrometeorology and air pollution in order to better adapt air quality policies.

\footnotetext{
*Corresponding author.

E-mail address: claire.sarrat@cnrm.meteo.fr (C. Sarrat).
}

Cities play a quite significant role on the local and regional scale meteorology. The morphological characteristics as well as the thermal and radiative properties of the built-up surfaces have a direct impact on the surface energy exchanges, which are quite different compared to those observed above natural soils and vegetation (Oke, 1987). At night under clear and calm conditions, a large temperature gradient develops between the city and its surroundings (Oke, 1982): such urban heat islands (UHI) were already documented for instance in Montreal (Oke and East, 1971), Paris (Escourrou, 1991), Toulouse (Estournel et al., 1983), Mexico (Oke et al., 1999) and Atlanta (Bornstein and Lin, 
2000). During the day, even if the UHI can also be observed, the dynamic processes are preponderant compared to the radiative and thermal effects. The dynamic roughness of the city favours the production of turbulence and the development of the urban boundary layer (UBL) (Dupont et al., 1999).

Human activities in urban and industrial areas are large sources of atmospheric pollutants. Their spatial distribution and their temporal evolution can be largely driven by thermodynamic and dynamic processes involved above the cities. Several experimental campaigns were conducted to document the atmospheric pollution in urban areas, for instance in Athens (Kambezidis et al., 1995), in Paris (Menut et al., 2000) and in Marseilles (Cros et al., 2004). In some studies, the interactions between air pollution and dynamics have been described, such as the role of sea breeze, land breeze and orographic flows (Henne et al., 2003; Cousin et al., 2005; Corsmeier et al., 2005). However, the coupling between the urban micrometeorology and the regional atmospheric pollution has not been studied in detail, except by Martilli et al. (2003) for the city of Athens, but in combination with strong land-sea breeze flows. The role of the urban processes related to the dynamics at smaller scales (e.g. due to an urban night time shallow convective boundary layer) have not yet been investigated.

This paper deals with the interaction between urban micrometeorology and atmospheric pollution. It is focused on Paris and its surroundings. The local topography is relatively smooth and the city is located inland far from the sea. As a result, the impact of the urban processes are preponderant and can be easily distinguished (Troude et al., 2002; Lemonsu and Masson, 2002). The aim of the present paper is to study the role of the city on the evolution of the atmospheric pollutant concentrations under an anticyclonic situation (16-18 July 1999). Three-dimensional simulations were conducted with the Meso-NH atmospheric model coupled to a chemistry module. The surface is represented by using a soil and vegetation scheme (Noilhan and Planton, 1989), and also a specific urban parameterization (Masson, 2000) in order to take into account the surface perturbations induced by the urban canopy and their influences on the structure of the atmosphere. Section 2 briefly presents the ESQUIF campaign and the meteorological episode, used in this study. After a description of the model and surface schemes in Section 3, in Sections 4 and 5 the numerical dynamic and chemical results are presented. In these sections, first there is an evaluation of the model against the observations, followed by a study of the inclusion of the urban processes.

\section{ESQUIF campaign}

\subsection{Experimental objectives}

A previous experiment on urban micrometeorology, ECLAP (French acronym for a boundary layer study in the Paris area), was conducted in the Paris area during the winter 1995. It focused on the dynamic processes but did not document the atmospheric pollution. Several works (Dupont et al., 1999; Troude et al., 2002) clearly show the significant effect of the urban area on the regional meteorology, i.e. the increase of turbulent kinetic energy (TKE), air temperature, and sensible heat flux in Paris.

The purpose of the ESQUIF (French acronym for study and simulation of air quality in the Ile de France region) campaign was to study both the dynamic and the chemical processes at the origin of the intense atmospheric pollution episodes observed in the Paris region. The experiment took place from 1998 to 2001. The project, described by Menut et al. (2000), provided meteorological observations and a large database on atmospheric pollution at the regional scale. The geographic location of Paris (Fig. 1), far from the coast, with a low topography, and far (about $200 \mathrm{~km}$ ) from other populated areas, makes this region an ideal place to study the respective contributions of dynamical and chemical processes to the photochemistry and to identify interactions between dynamics and air pollution. This project also attempts to improve atmospheric chemistry in numerical models (Beekman and Derognat, 2003; Blond et al., 2003; Derognat et al., 2003; Menut, 2003; Schmidt and Martin, 2003; Sillman et al., 2003; Vautard et al., 2003a; Solmon et al., 2004) and knowledge about air quality in general (Vautard et al., 2003b).

\subsection{IOP presentation}

This study focuses on the ESQUIF intensive observation period (IOP) 6, which took place between 16th and 18th of July, 1999 (the three successive days will be hereafter referred as JY16, JY17 and JY18). This period corresponded to an anticyclonic situation with significant solar 


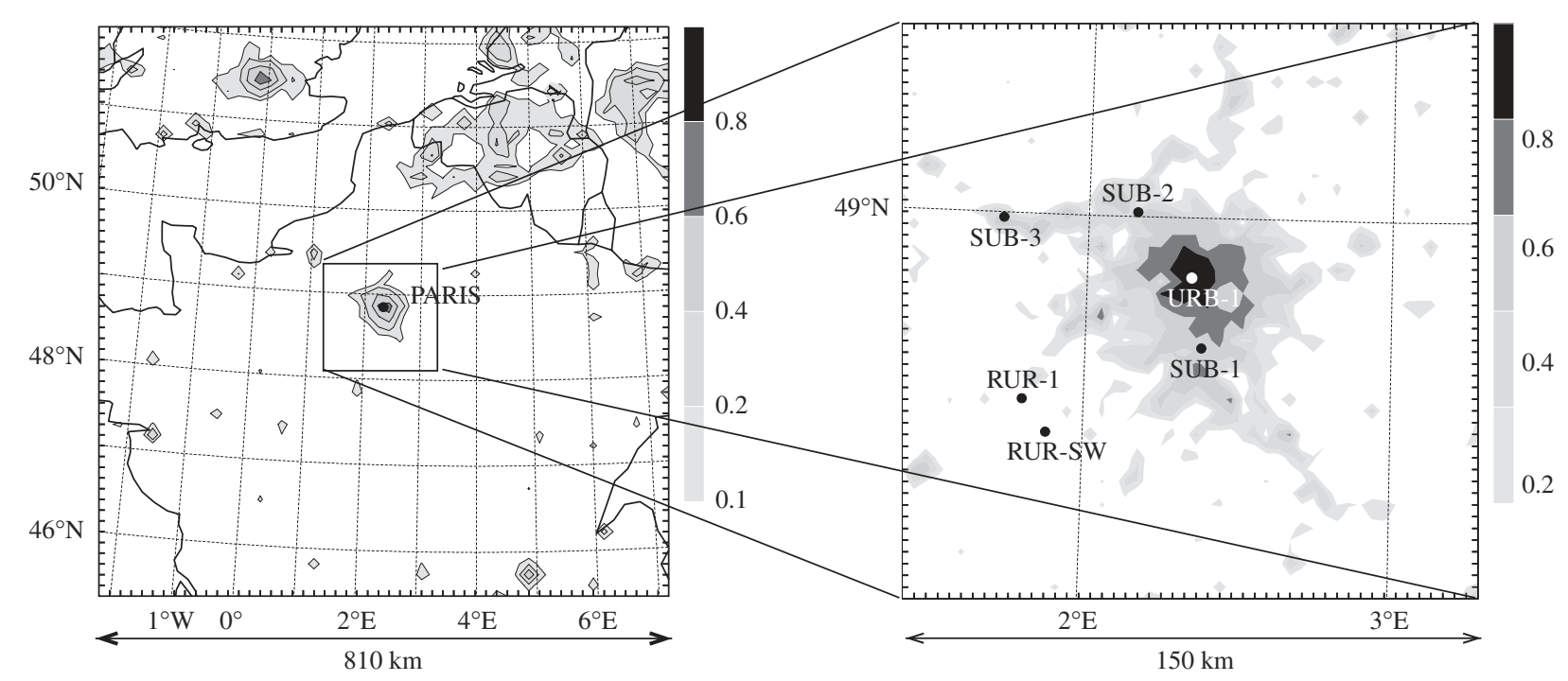

Fig. 1. Large and small domains of simulation. Urban fractions are shaded. The studied stations are labelled on the small domain.

radiation and weak winds $\left(2 \mathrm{~ms}^{-1}\right.$ observed near the surface in Paris). Observed air temperatures increased during the IOP, reaching a maximum of $33^{\circ} \mathrm{C}$ in Paris on JY18. The same evolution was observed for the boundary layer height (BLH) measured by radiosounding, which reached $1000 \mathrm{~m}$ on JY16, $1200 \mathrm{~m}$ on JY17 and $1700 \mathrm{~m}$ on JY18.

Owing to such meteorological conditions, this period is ideal for documenting the development of atmospheric pollution over a large urban area: high temperatures and large insolation (no clouds observed) generated a large ozone plume $\left(\mathrm{O}_{3}\right)$, with high concentrations in the city but also in rural areas. $\mathrm{O}_{3}$ concentrations recorded by the local air quality network in Paris reached 70 ppbv on JY16, 85 ppbv on JY17 and 90 ppbv on JY18. The location of the regional ozone maximum varied from day to day from the south-east to the west and north of Paris, on JY16, JY17 and JY18, respectively, with concentration peaks of 83,135 and 97 ppbv. The ozone peak observed on JY17 was correlated with a nitrogen oxide $\left(\mathrm{NO}_{x}\right)$ peak the same day. More than 100 ppbv of $\mathrm{NO}_{x}$ were observed on this day in Paris and also in suburban areas, whereas the concentrations on other days did not exceed $60 \mathrm{ppbv}$ in Paris and $30 \mathrm{ppbv}$ around the city.

\section{Presentation of the simulation}

\subsection{Generalities and modelling configuration}

Simulations are performed with the Meso-NHC model, in which the Meso-NH atmospheric model
(Lafore et al., 1998) is coupled on-line with a chemistry module (Suhre et al., 1998; Tulet et al., 1999).

Meso-NH is a non-hydrostatic meso-scale atmospheric model allowing two-way nesting simulations. The vertical grid, which is composed of 60 levels, has a higher resolution close to the surface in order to obtain a detailed description of the atmospheric boundary layer (ABL). The model is initialized and forced at the lateral boundaries every $3 \mathrm{~h}$ by ARPEGE, the French forecast model for dynamic parameters and by the global chemical transport model (CTM) MOCAGE (Puech and Amodei, 1999; Cathala et al., 2003) for all chemical species. In this study, the chosen configuration is composed of two nested domains (see Fig. 1). The large-scale domain has a resolution of $15 \mathrm{~km}$ and covers an area of $810 \times 810 \mathrm{~km}^{2}$. The small model has a resolution of $3 \mathrm{~km}$ and covers $150 \times 150 \mathrm{~km}^{2}$. Two simulations are performed with the same configuration, i.e. same domains, initialization fields, forcing fields and physical parameterizations. The only difference is the surface: (1) the first simulation (called URBAN hereafter) is performed with a specific urban parameterization. In this case, the energy fluxes are computed by the town energy balance (TEB) urban surface scheme (Masson, 2000) above urban artificial surfaces, and by the interaction soil-biosphere-atmosphere (ISBA) scheme (Noilhan and Planton, 1989) above natural surfaces. (2) The other simulation (called NO-URB hereafter) is conducted without the TEB urban surface scheme. In this case, the urban land-use 
covers are replaced by natural surface, similar to one of the surrounding rural areas. As a consequence, the fluxes are calculated everywhere according to ISBA.

Both simulations start on JY16 at 0000 UTC and are run continuously until JY17 at 2000 UTC.

\subsection{On-line coupled chemistry meteorological model}

The chemical scheme is the regional lumped atmospheric chemical scheme (ReLACS) (Crassier et al., 2000) obtained through the reduction of the regional atmospheric chemistry mechanism (RACM) (Stockwell et al., 1997). One major sink for several species is surface deposition. The Wesely (1989) parameterization has been selected in MesoNHC model and is implemented into the ISBA and the TEB surface schemes. Anthropogenic emissions of gas phase primary species are provided by the GENeration of an EMISsion (GENEMIS) inventory database for Europe (Wickert et al., 1999), accounting for anthropogenic sources like traffic, industry, solvent use, waste treatment and agriculture. It consists in hourly emission inventory at a $3 \mathrm{~km}$ horizontal resolution in the Paris region and $9 \mathrm{~km}$ elsewhere. Primary compounds contained in the database are $\mathrm{NO}_{x}$, carbon monoxide $(\mathrm{CO})$, sulfur dioxide $\left(\mathrm{SO}_{2}\right)$, and 32 hydrocarbon classes. The parameterization of biogenic emissions in Meso-NHC is based upon Guenther's algorithms (Guenther et al., 1993). Fluxes of isoprene and monoterpenes ( $\alpha$-pinene and d-limonene only) are computed at each time step (Solmon et al., 2004).

\subsection{TEB urban scheme}

TEB is a surface scheme which parameterizes water and energy exchanges between urban surfaces and the atmosphere. It is based on the concept of an urban canyon developed by Nunez and Oke (1977) and generalized to large urban areas. The urban canopy is represented for each mesh by an averaged and ideal urban canyon, composed of one horizontal road, one horizontal roof and two identical perpendicular walls (see Fig. 1 in Masson, 2000), defined by mean geometric parameters (building height, width of buildings and streets, and urban dynamical roughness length), and by thermal and radiative properties of the corresponding materials (albedos, emissivities, thermal conductivities and heat capacities). The radiative and energy budgets are computed for each urban surface (road, roof, wall). This concept enables the simple but realistic representation of the complex three-dimensional geometry of urban canopies at the city scale. TEB is already coupled with Meso-NH and was used for dynamical studies for Paris (Lemonsu and Masson, 2002) and Marseilles (Lemonsu et al., 2005).

\section{Dynamical impact of the urban area}

\subsection{Evaluation of the atmospheric model}

Measurements from 24 Météo France operational network stations were available in the modelling domain. Four of them are located inside Paris, corresponding to dense urban areas with an urbanization rate greater than $50 \%$, defined from the CORINE Land Cover database (CEC, 1993). Thirteen are located in suburban areas around the city, their urbanization rates being between $10 \%$ and $50 \%$. The others are located in rural areas, where the urbanized fractions are negligible. To evaluate the dynamical variables of the model and to study the effect of the urban parameterization used in the simulation, the modelled $2 \mathrm{~m}$ air temperature and specific humidity of both URBAN and NO-URB simulations are compared to the observations. Fig. 2 presents the temporal evolution of air temperature and specific humidity for three stations, which illustrate the three urbanization classes. The urban station (URB-1), whose urbanization rate is about $90 \%$, is located in the Paris city core (4th district). The suburban station (SUB-1), located at Athis-Mons in the south of Paris, is composed of similar fractions of natural and urban covers. For the rural station (RUR-1), located at Orcemont in the south-west of Paris, natural soils and vegetation are largely predominant. These three stations are labelled in Fig. 1. The statistical scores, however, are computed for the 24 stations of the network (Table 1).

On the one hand in the rural case, the results are quite similar between both simulations and in good agreement with the observations. For such areas, the implementation of TEB does not have a significant impact on the meteorological parameters because the urban cover fractions are very low. On the other hand, the comparison shows strong temperature and humidity differences in urban and suburban cases, for which the fractions of covers treated by TEB are preponderant. The URBAN simulation always shows better results in terms of air temperature and specific humidity for 

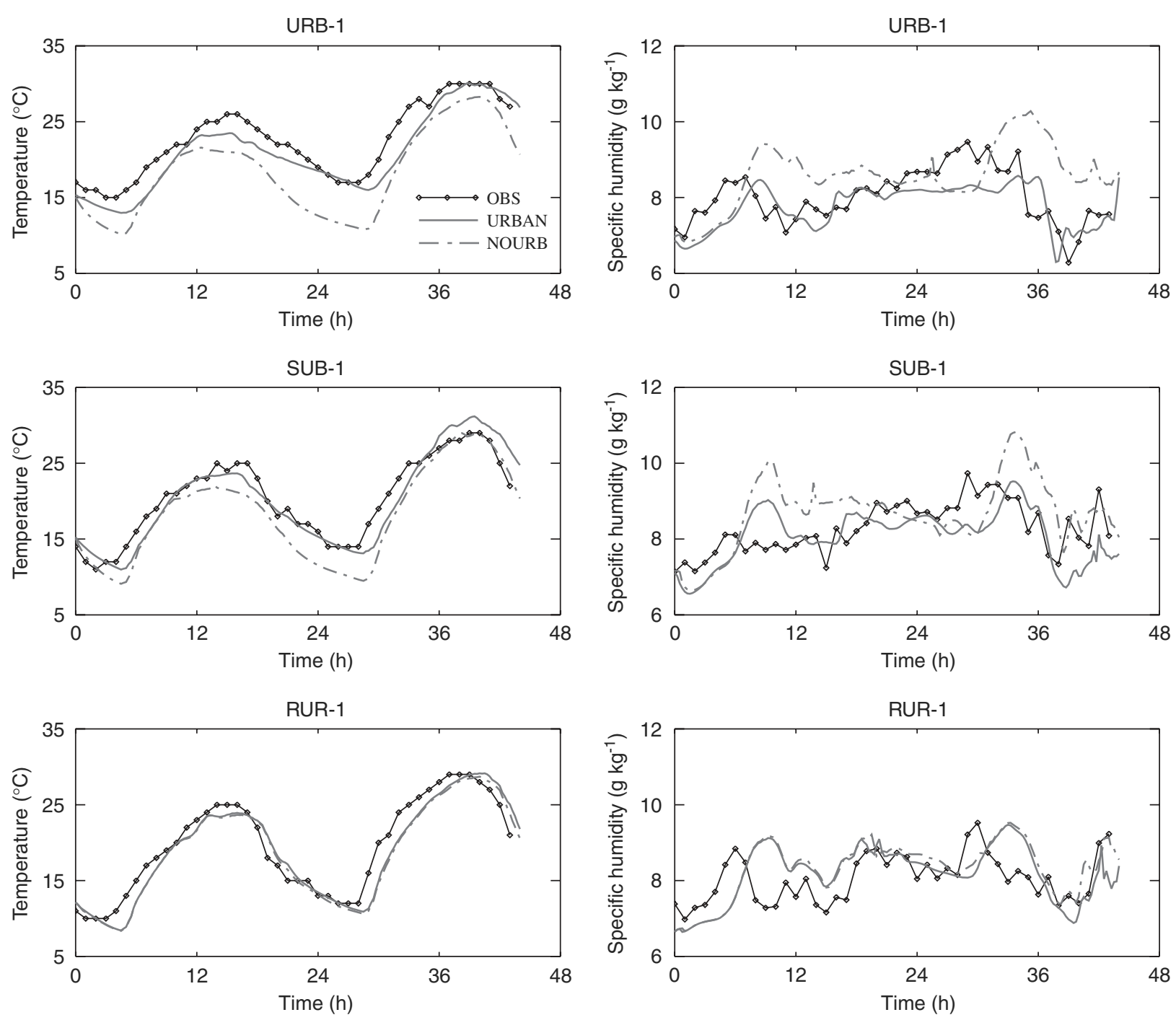

Fig. 2. Comparison between observed and modelled URBAN and NO-URB $2 \mathrm{~m}$ air temperature and specific humidity for urban, suburban and rural stations.

all the urban and suburban stations (see Fig. 2 and scores in Table 1). This underscores that the mechanisms of energy exchanges are significantly different above the vegetated and the urban canopies. The TEB scheme takes into account the complex three-dimensional geometry of the urban canopy and the specific thermal and radiative properties of artificial materials (see Section 3.3). As a consequence, the built-up surfaces strongly warm up during daytime and store much more heat than the natural covers. This heat is released at night, which limits the nocturnal cooling of the near-surface air. This process has a major impact on the $2 \mathrm{~m}$ air temperature, which stays much larger in URBAN than in NO-URB, between 0000 and 0600
UTC. The maximum difference reaches about $4{ }^{\circ} \mathrm{C}$ in suburban areas and more than $6^{\circ} \mathrm{C}$ in dense urban areas at 0400 UTC. The air humidity is also influenced. The comparisons between URB-1, SUB1 and RUR-1 reveal a decrease of the specific humidity at midday in the urban and the suburban areas which is not observed in rural area. This is only reproduced by the URBAN simulation.

The simulation evaluation presents satisfying results for the modelling of the near-surface meteorological parameters by Meso-NH. This is in accordance with the air temperature and humidity observations, which show that urban effects exist and that the behaviours differ between the urban and rural stations. 
Table 1

Rmse and bias (Obs-Model) of $2 \mathrm{~m}$ air temperature (Unit K) and $2 \mathrm{~m}$ specific humidity (Unit $\mathrm{g} \mathrm{kg}^{-1}$ ) computed for all the stations (Global), and independently for the urban (URB), the suburban (SUB), and the rural (RUR) stations

\begin{tabular}{|c|c|c|c|c|c|c|c|c|}
\hline & \multicolumn{2}{|l|}{ Global } & \multicolumn{2}{|l|}{ URB } & \multicolumn{2}{|l|}{ SUB } & \multicolumn{2}{|l|}{ RUR } \\
\hline & URBAN & NO-URB & URBAN & NO-URB & URBAN & NO-URB & URBAN & NO-URB \\
\hline \multicolumn{9}{|l|}{$\mathrm{T} 2 \mathrm{~m}$} \\
\hline Rmse & 2.2 & 2.9 & 2.5 & 4.0 & 2.1 & 2.7 & 2.2 & 2.3 \\
\hline Bias & +0.9 & +2.0 & +0.6 & +3.0 & +1.0 & +2.1 & +0.9 & +1.2 \\
\hline \multicolumn{9}{|l|}{$\mathrm{Rv} 2 \mathrm{~m}$} \\
\hline Rmse & 0.8 & 0.9 & 0.9 & 1.1 & 0.7 & 0.9 & 0.8 & 0.8 \\
\hline Bias & +0.2 & -0.2 & +0.5 & -0.3 & +0.2 & -0.1 & -0.2 & -0.2 \\
\hline
\end{tabular}

For each case, results of both URBAN and NO-URB are presented.

URBAN SIMUL : Potential Temperature $\left({ }^{\circ} \mathrm{C}\right)$ 07/17/99 0000 UTC

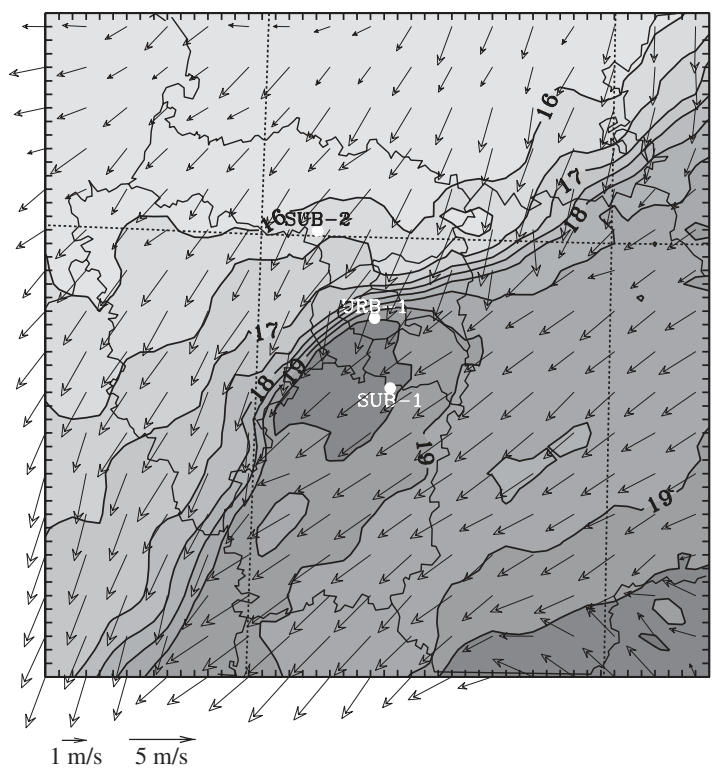

(a)
NO-URB SIMUL : Potential Temperature $\left({ }^{\circ} \mathrm{C}\right)$ 07/17/99 0000 UTC
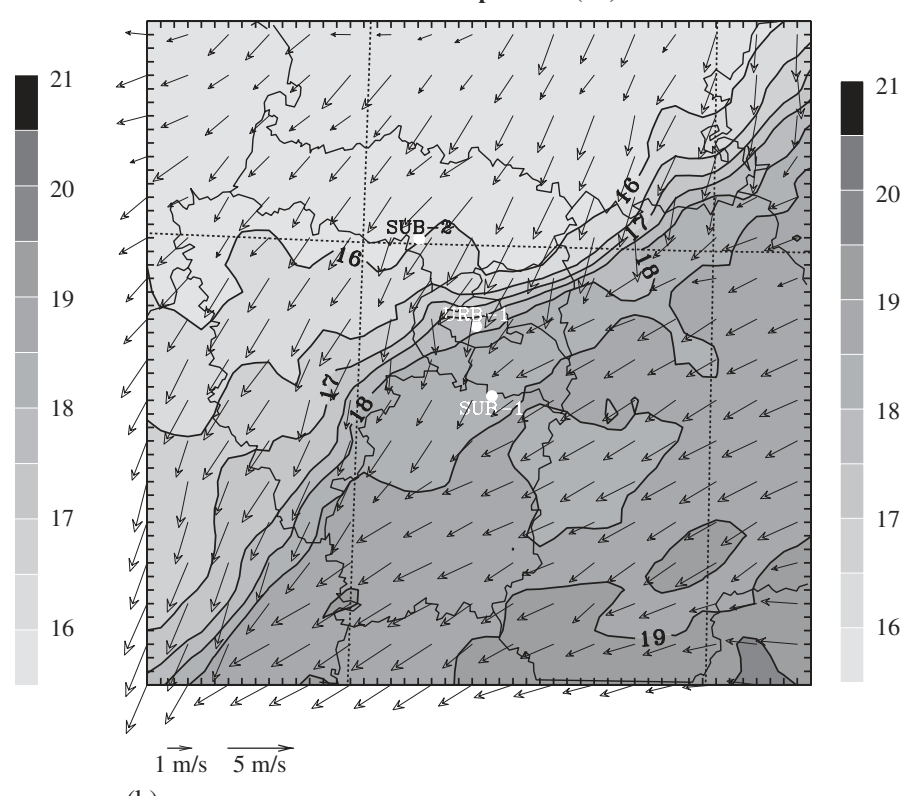

(b)

Fig. 3. Modelled horizontal fields of potential temperature on JY17 at 0000 UTC at $20 \mathrm{~m}$ above the canopy for: (a) URBAN and (b) NOURB simulations.

\subsection{Nocturnal situation of $J Y 17$}

In this section, particular attention is given to the processes which occur during the night between JY16 and JY17. Both URBAN and NO-URB modelled fields of potential temperature at the first atmospheric level (20 $\mathrm{m}$ above the canopy) at 0000 UTC (Fig. 3) reveal a temperature gradient from north-west to south-east (the north-west being colder than the south-east), associated with a convergence area south-west of Paris. In addition, URBAN clearly reveals the presence of an UHI over Paris reaching up to $5^{\circ} \mathrm{C}$, which is not observed in NO-URB. Because of the regional-scale temperature gradient, the UHI intensity is not spatially homogeneous: it is about $1.0-1.5^{\circ} \mathrm{C}$ between Paris and the eastern countryside, while it reaches more than $3.5^{\circ} \mathrm{C}$ west of the domain. Under the effect of the synoptic wind, the UHI is displaced to the south-west and forms an urban plume, which transports warm air above the surrounding suburban areas.

According to model outputs, the station SUB-1 (Fig. 3) is affected by this urban plume, the air temperature being $1.5^{\circ} \mathrm{C}$ warmer than in NO-URB. The comparison of air temperature measured in 
SUB-1 and the other suburban station SUB-2 (not shown here), located in the north-east of Paris (both are labelled in Fig. 3), illustrates the effect of this atmospheric circulation. These stations have approximately the same urbanization rate $(45 \%$ and $50 \%$, respectively) but are located in different places. While both $2 \mathrm{~m}$ air temperatures simulated in SUB-1 and SUB-2 are quite similar in the NOURB simulation, in the URBAN one, the UHI advection in the south-west of Paris above SUB-1 increases the temperature up to $17^{\circ} \mathrm{C}$ while it remains at $14{ }^{\circ} \mathrm{C}$ in SUB-2, in the north of Paris.

\subsection{Diurnal situation of JY17}

During the daytime, the urban processes are different. While they are primarily of thermal origin at night, a coupling of thermal and dynamical effects occurs in the afternoon.

At 1700 UTC, the synoptic scale flow originated in the east and the main temperature gradient was from north to south. A UHI is still observed in URBAN (Fig. 4), but its intensity is less during the night (a maximum of $2{ }^{\circ} \mathrm{C}$ with the northern countryside). The local wind is also affected by the urban covers because of the high dynamic roughness of the city. According to the comparison between URBAN and NO-URB horizontal wind

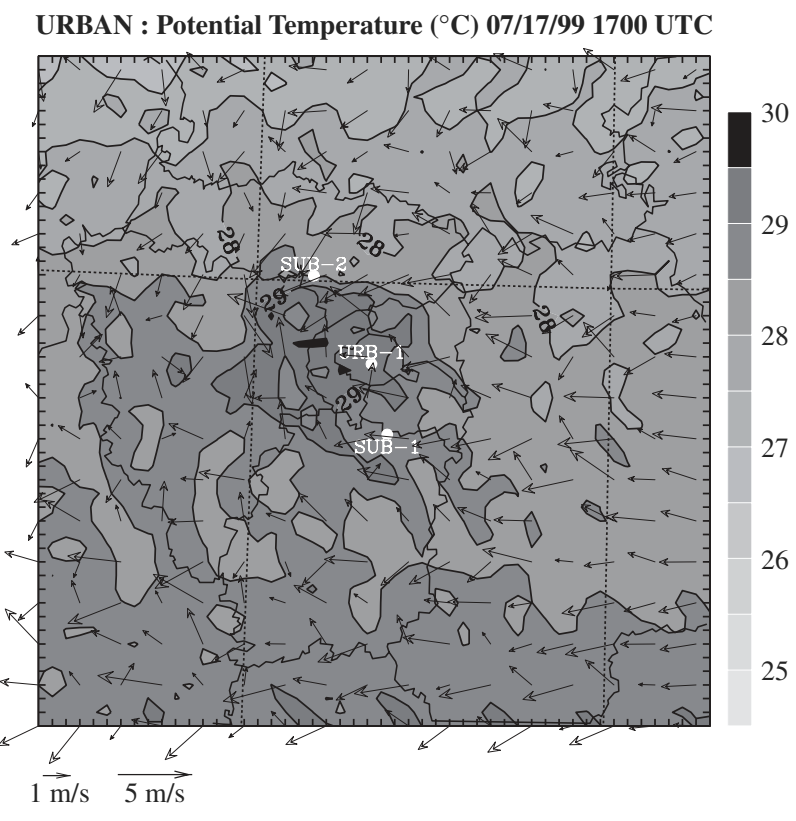

(a) at $20 \mathrm{~m}$ above the canopy, the easterly wind is disturbed over the suburban areas located south of Paris. The modification of the wind orientation in URBAN seems to have a direct impact on the potential temperature field. More specifically, it seems to limit the cooling westward.

As in Lemonsu and Masson (2002), the top of the ABL is higher over Paris in URBAN than in NOURB, because the built-up surfaces and especially their roughness favour the production of TKE during the day. The maximum difference is about $300 \mathrm{~m}$, the top of the ABL reaching 2200 and $1900 \mathrm{~m}$ in URBAN and NO-URB, respectively.

\section{Impact of urban meteorology on pollutant distribution}

Paris and its suburbs are strong emitters of anthropogenic primary pollutants, like $\mathrm{NO}_{x}$ and volatile organic compounds (VOC). By influencing and modifying the thermal and dynamical structure of the ABL, the urban effects have a significant impact on the availability and the advection/ dispersion of primary and secondary compounds. This section investigates how the local spatial distribution of primary and secondary pollutants is affected by the urban meteorology.

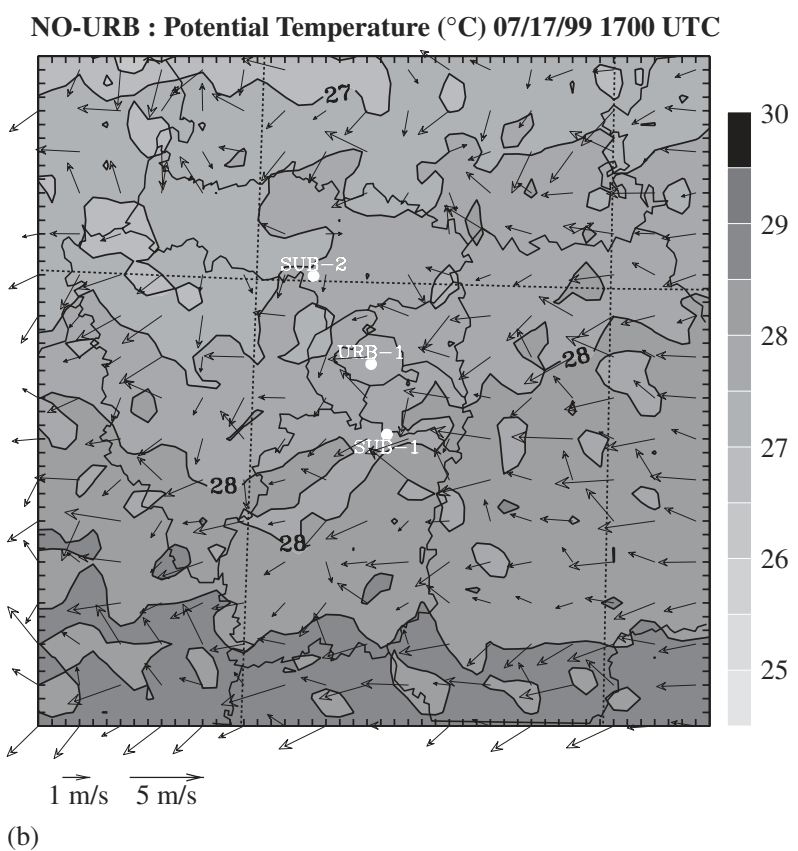

Fig. 4. Modelled horizontal fields of potential temperature on JY17 at 1700 UTC at $20 \mathrm{~m}$ above the canopy for: (a) URBAN and (b) NOURB simulations. 


\subsection{Evaluation of the chemistry simulation}

Fig. 5 presents the comparisons between observed and modelled (URBAN and NO-URB) $\mathrm{O}_{3}$ and $\mathrm{NO}_{x}$ concentrations for the three types of land cover: (a) urban (URB-1), (b) suburban (SUB-3) and (c) rural (RUR-SW). All are labelled in Fig. 1. As for the dynamic comparisons, the modelled $\mathrm{O}_{3}$ concentrations of the URBAN and NO-URB simulations are quite similar for both the suburban and the rural stations. They reproduce the higher $\mathrm{O}_{3}$ concentrations generally observed on the second day JY17 for all the stations and more specifically the ozone plume over the SUB-3 region (almost 140 ppbv measured during the JY17 afternoon). But they also indicate a systematic overestimation of the model which is confirmed by the statistical scores computed for 10 stations within the large Paris region (Table 2), whereas the general pattern is correctly modelled. Nocturnal ozone concentrations at URB-1 are overestimated in URBAN and underestimated in NO-URB, but the pattern of the concentration evolution in the afternoon is more realistic in URBAN than in NO-URB. This is due to a better representation of $\mathrm{NO}_{x}$ in URBAN. Indeed, the strong decrease of $\mathrm{O}_{3}$ concentration observed in NO-URB between 1900 and 0000 UTC is directly related to the peak of $\mathrm{NO}_{x}$ modelled in the evening but in disagreement with the observations. These differences are also confirmed by the statistical scores (Table 2). They indicate that URBAN reproduces better ozone concentrations than NO-URB, except at the suburban stations. Such areas are quite difficult to represent because of the strong ozone concentration gradients. Finally, the global scores on ozone concentration are equivalent for both simulations.

Concerning $\mathrm{NO}_{x}$ concentrations, the URBAN results are better than those of NO-URB for all classes of stations according to both the RMSE and the bias (Table 2). Generally, NO-URB tends to overestimate the $\mathrm{NO}_{x}$ concentrations, which is also confirmed by the airborne data. During the afternoon of JY17, the ARAT aircraft measured pollutant concentrations over suburban and rural areas around Paris (the horizontal projection of the aircraft trajectory is represented in Fig. 6b). The comparison between these observations and both simulations shows that both URBAN and NO$\mathrm{URB}$ overestimate $\mathrm{NO}_{y}$ concentrations inside the plume by several tens of ppbv, but that the location of the plume is well represented by the model. Inside the plume, the URBAN ozone concentrations are in better agreement with observations than the NOURB concentrations at 1730 UTC. The statistical scores computed for this flight (Table 3) display that ozone, $\mathrm{NO}_{x}$ and $\mathrm{NO}_{y}$ RMSE are lower for URBAN than for NO-URB.

These comparisons point out that the contribution of the UHI and the modified ABL to the
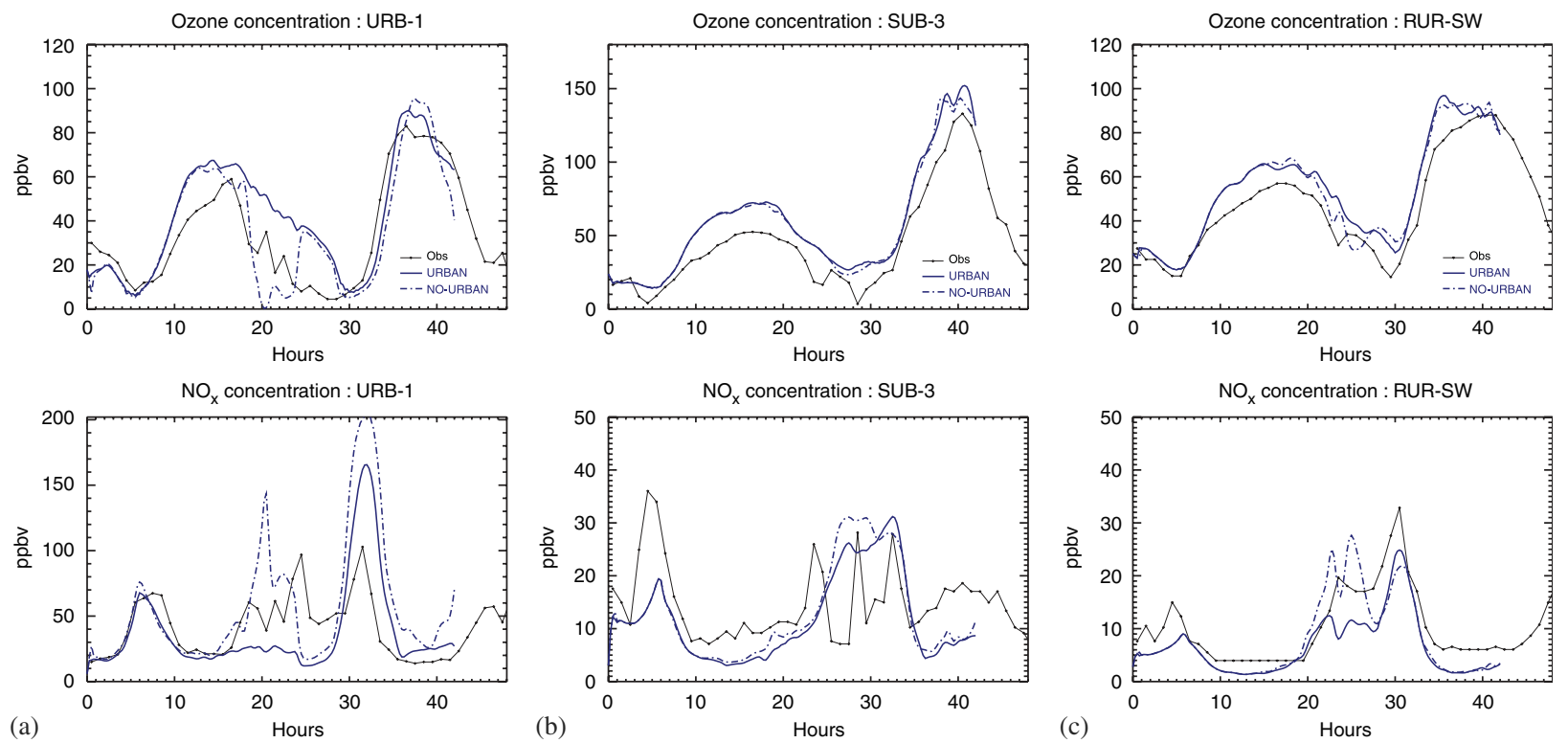

Fig. 5. Time series of $\mathrm{O}_{3}$ and $\mathrm{NO}_{x}$ observed and modelled with URBAN (solid line) and NO-URB (dashed line): (a) in Paris, (b) in a suburban site SUB-3 and (c) in a rural site RUR-SW. 
Table 2

Rmse and bias (Obs-Model) of $\mathrm{O}_{3}$ and $\mathrm{NO}_{x}$ (Unit ppb) computed for 11 stations (Global), and independently for 3 urban stations (URB), 3 suburban stations (SUB), and 4 rural stations (RUR) stations

\begin{tabular}{|c|c|c|c|c|c|c|c|c|}
\hline \multirow[t]{2}{*}{ Stations type simulation } & \multicolumn{2}{|l|}{ Global } & \multicolumn{2}{|l|}{ URB } & \multicolumn{2}{|l|}{ SUB } & \multicolumn{2}{|l|}{ RUR } \\
\hline & URBAN & NO-URB & URBAN & NO-URB & URBAN & NO-URB & URBAN & NO-URB \\
\hline \multicolumn{9}{|l|}{$\mathrm{O}_{3}$} \\
\hline Rmse & 17.7 & 17.7 & 14.8 & 15.3 & 16.7 & 14.9 & 20.1 & 20.9 \\
\hline Bias & -11.6 & -8.6 & -5.9 & +1.7 & -11.0 & -8.4 & -16.2 & -16.6 \\
\hline \multicolumn{9}{|l|}{$\mathrm{NO}_{x}$} \\
\hline Rmse & 19.4 & 29.8 & 31.0 & 50.4 & 15.7 & 19.0 & 5.8 & 6.1 \\
\hline Bias & -3.2 & -11.0 & -5.7 & -26.3 & -0.1 & -5.4 & -3.6 & -3.8 \\
\hline
\end{tabular}

For each case, results of both URBAN and NO-URB are presented.
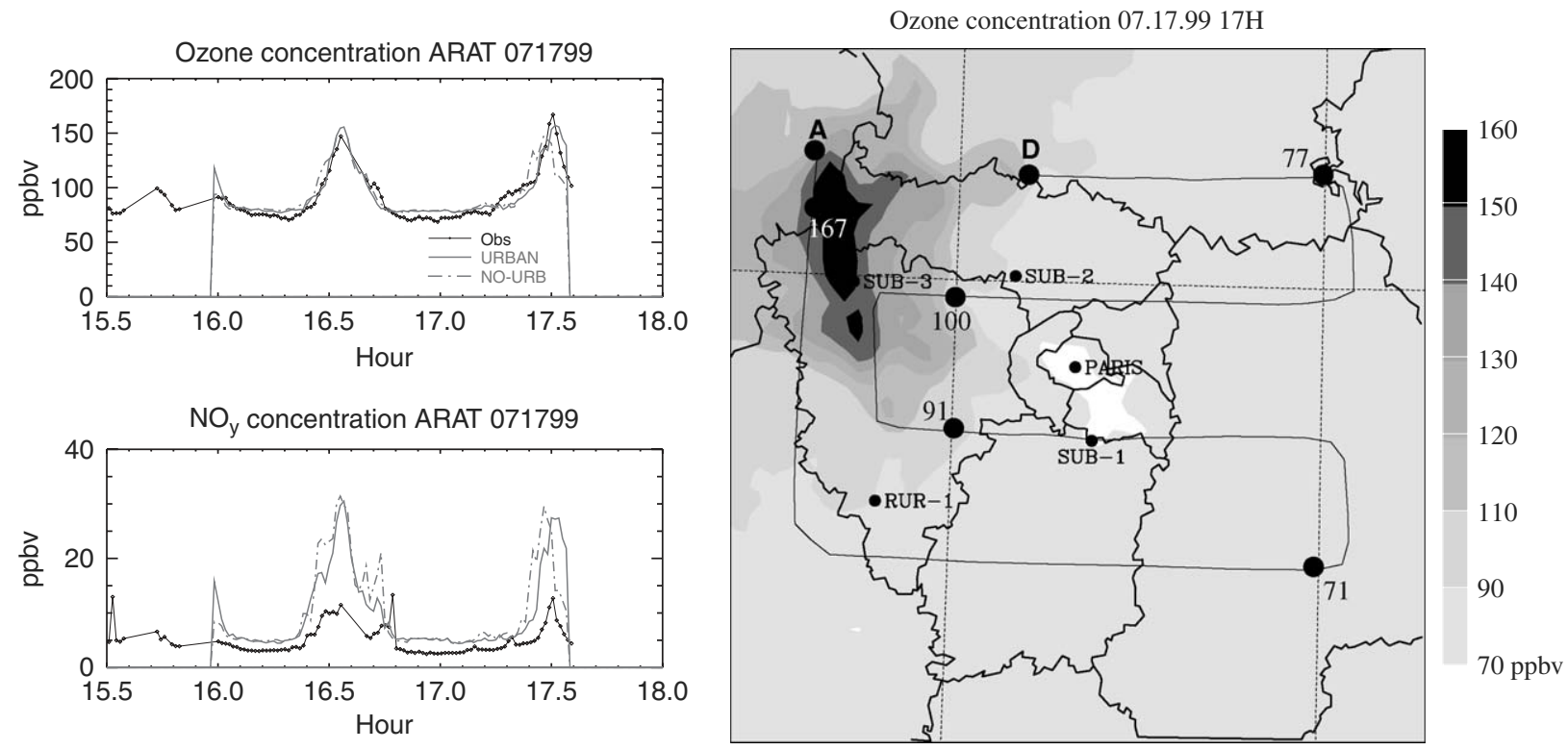

(b)

(a)

Fig. 6. (a) Time series of $\mathrm{O}_{3}$ and $\mathrm{NO}_{x}$ measured by aircraft on JY17 at $900 \mathrm{~m}$ above the ground and modelled with URBAN and NO-URB and (b) aircraft trajectory superimposed on URBAN horizontal field of $\mathrm{O}_{3}$ modelled at $900 \mathrm{~m}$ above the ground at $1700 \mathrm{UTC}$. The ozone concentrations measured during the flight are also labelled on the aircraft trajectory.

pollutant spatial distribution is more important for $\mathrm{NO}_{x}$ than for $\mathrm{O}_{3}$ because the processes which drive the $\mathrm{NO}_{x}$ concentrations are involved at the local scale, whereas the formation of a secondary pollutant such as ozone is a regional scale phenomenon. Nevertheless, the dynamical processes generated by the urban covers are crucial for a good modelling of primary pollutants such as nitrogen oxides. The nighttime UHI over Paris simulated by URBAN and the associated turbulence enable a better representation of the ABL over the city and its surroundings. As shown in the next section, the $\mathrm{NO}_{x}$ concentrations are quite dependent on turbu- lent fluxes. Finally, the differences between both simulations clearly evidence the relevance of implementing a specific urban parameterization in the atmospheric model.

\subsection{Effect of the nocturnal urban heat island}

At 0000 UTC, the comparison of $\mathrm{NO}_{x}$ concentration fields simulated at the first atmospheric level by URBAN and NO-URB (Fig. 7) shows that the distribution over Paris is completely different between the two cases. On the one hand, southwest of Paris (in the convergence area identified in 
Fig. 3) the NO-URB $\mathrm{O}_{3}$ concentrations are very low, i.e. a few ppbv only, when the background concentrations are around 40-60 ppbv. Conversely, the NO-URB $\mathrm{NO}_{x}$ concentrations are much higher in the convergence area (i.e. around $100 \mathrm{ppbv}$ ) than in the rest of the region where they remain lower than 20 ppbv. On the other hand, both URBAN $\mathrm{O}_{3}$ and $\mathrm{NO}_{x}$ concentration fields present much more homogeneous values with the concentration differences between the convergence area and the surroundings not exceeding $20 \mathrm{ppbv}$. The horizontal and vertical distribution of nighttime $\mathrm{O}_{3}$ concentra-

Table 3

Rmse and bias (Obs-Model) of $\mathrm{O}_{3}, \mathrm{NO}_{x}$ and $\mathrm{NO}_{y}$ (Unit ppbv) computed for the ARAT flight on JY17

\begin{tabular}{lcc}
\hline & URBAN & NON-URB \\
\hline $\mathrm{O}_{3}$ & & \\
$\quad \mathrm{Rmse}$ & 8.6 & 9.7 \\
$\quad$ Bias & -2.1 & -2.3 \\
$\mathrm{NO}_{x}$ & & \\
$\quad$ Rmse & 1.2 & 1.9 \\
Bias & +0.4 & 0.1 \\
$\mathrm{NO}_{y}$ & & \\
$\quad$ Rmse & 6.4 & 7.3 \\
Bias & -4.2 & -4.8 \\
\hline
\end{tabular}

URBAN SIMUL : NO $($ ppbv), 07/17/99 0000 UTC

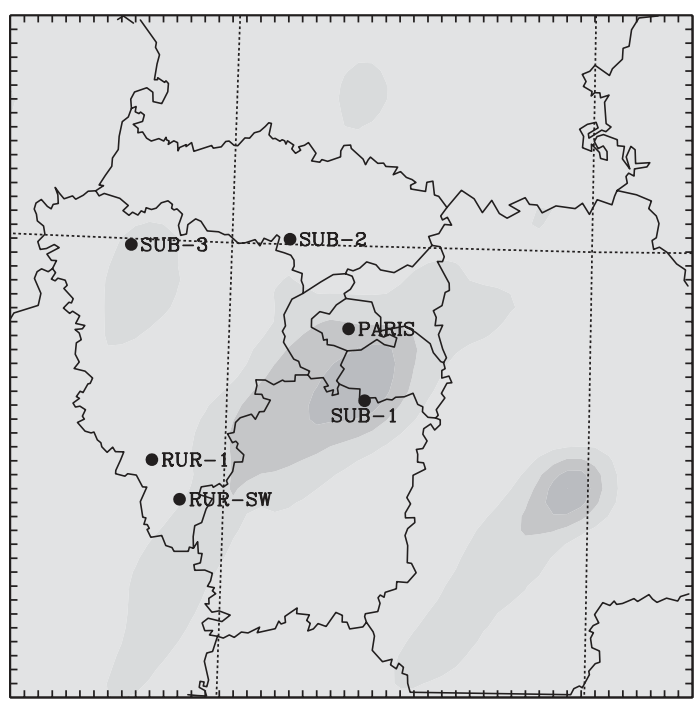

(a) tion is related to $\mathrm{NO}_{x}$ concentrations because at night, the only path for ozone is the chemical destruction together with the dry deposition on the surface:

$\mathrm{NO}+\mathrm{O}_{3} \rightarrow \mathrm{NO}_{2}+\mathrm{O}_{2}$,

where $\mathrm{NO}, \mathrm{NO}_{2}$ and $\mathrm{O}_{2}$ are nitrogen monoxide, nitrogen dioxide and dioxide, respectively. As a consequence, the minimum $\mathrm{O}_{3}$ concentration corresponds to the maximum $\mathrm{NO}_{x}$ concentration. Especially in case of NO-URB, the high concentrations of nitrogen oxides simulated in the convergence zone destroy all available $\mathrm{O}_{3}$ (little dry deposition as calculated in Table 4), whereas the $\mathrm{NO}_{x}$ concentrations of URBAN are insufficient near the surface to destroy all $\mathrm{O}_{3}$. Note that this coupling between $\mathrm{NO}_{x}$ and $\mathrm{O}_{3}$ was also underscored in Fig. 5 between 1900 and 0000 UTC (Section 5.1).

In order to understand why the urban parameterization has such an impact on the distribution of ozone and nitrogen oxides in the simulation, the respective contributions of the various physical phenomena in interaction have been evaluated for $\mathrm{NO}$ and $\mathrm{O}_{3}$. Budgets have been calculated between 2300 and 0000 UTC at the first atmospheric level of the model (i.e. $20 \mathrm{~m}$ above the canopy). The budget terms for the chemical species are: advective tendency (ADV), chemical production/loss tendency

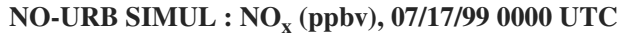

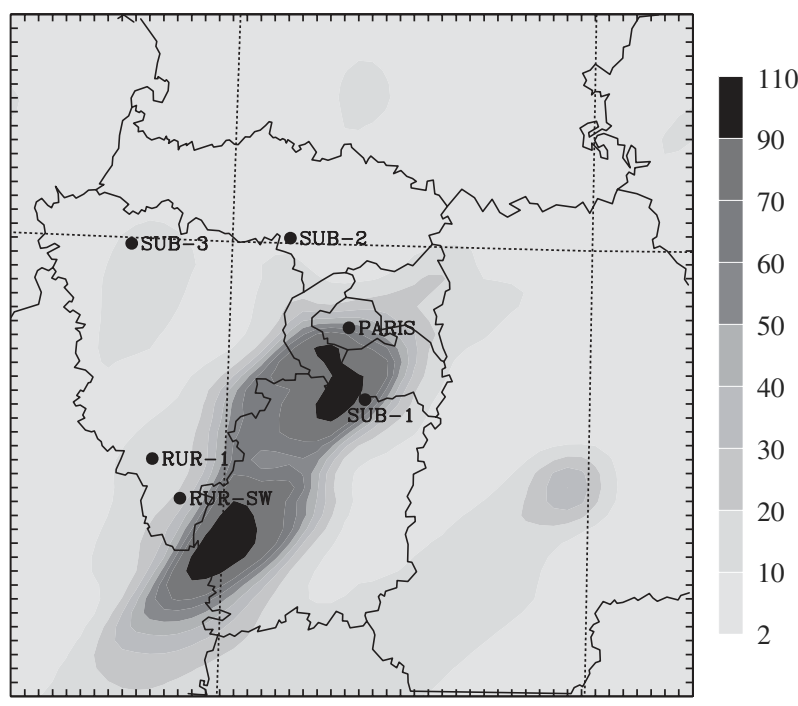

(b)

Fig. 7. Modelled horizontal field of $\mathrm{NO}_{x}$ concentrations (ppbv) on JY17 at 0000 UTC at $20 \mathrm{~m}$ above the canopy for: (a) URBAN and (b) NO-URB simulations. 
Table 4

Components of the hourly budget computed for $\mathrm{NO}$ and $\mathrm{O}_{3}$ at nighttime, between 2300 and $0000 \mathrm{UTC}\left(\mathrm{Unit}_{\mathrm{ppbvh}}{ }^{-1}\right)$

\begin{tabular}{|c|c|c|c|c|c|c|}
\hline & Gain/loss & CHEM & TURB & $\mathrm{ADV}$ & DEP & EMIS \\
\hline \multicolumn{7}{|c|}{ SUB-1 nighttime NO budget } \\
\hline NO-URB & +4.8 & -30.0 & -3.0 & 5.5 & 0.0 & 30.0 \\
\hline URBAN & +0.0 & -27.0 & -3.5 & 0.8 & 0.0 & 30.0 \\
\hline \multicolumn{7}{|c|}{ URB-1 nighttime NO budget } \\
\hline NO-URB & -3.6 & -45.6 & -6.0 & -6.0 & 0.0 & 50.0 \\
\hline URBAN & -0.2 & -45.0 & -10.0 & 0.1 & 0.0 & 50.0 \\
\hline \multicolumn{7}{|c|}{ SUB-1 nighttime $\mathrm{O}_{3}$ budget } \\
\hline NO-URB & -3.7 & -25.7 & 17.6 & 4.4 & -1.0 & 0.0 \\
\hline URBAN & -5.7 & -25.5 & 32.9 & -5.7 & -7.4 & 0.0 \\
\hline
\end{tabular}

(CHEM), the turbulent tendency (TURB), dry deposition tendency (DEP) and anthropogenic emissions (EMIS). Consequently, the net tendency for a given chemical species $C$ is

$$
\begin{aligned}
\frac{\mathrm{d} C}{\mathrm{~d} t}= & \left.\frac{\mathrm{d} C}{\mathrm{~d} t}\right|_{\text {advection }}+\left.\frac{\mathrm{d} C}{\mathrm{~d} t}\right|_{\text {turbulence }}+\left.\frac{\mathrm{d} C}{\mathrm{~d} t}\right|_{\text {chemistry }} \\
& +\left.\frac{\mathrm{d} C}{\mathrm{~d} t}\right|_{\text {deposition }}+\left.\frac{\mathrm{d} C}{\mathrm{~d} t}\right|_{\text {emission }} \\
= & \text { ADV + TURB + CHEM + DEP + EMIS. }
\end{aligned}
$$

Each process $P$ of Eq. (2) is computed at each grid point and averaged with a $1 \mathrm{~h}$ timestep following:

$\frac{1}{t_{2}-t_{1}} \sum_{t_{1}}^{t_{2}} P_{t} \Delta t$

where $t_{2}-t_{1}$ corresponds to the averaging budget time interval ( $1 \mathrm{~h}$ in the present case) and $\Delta t$ the model time step. All the terms of the hourly budget are summarized in Table 4 (nighttime budget) and in Table 5 (daytime budget).

The primary pollutant NO budget has been calculated for the two sites URB-1 and SUB-1 (Table 4). The EMIS term is associated with anthropogenic emissions provided to the model by GENEMIS (Section 3.2). Thus, EMIS ${ }^{\text {URBAN }}=$ EMIS $^{\mathrm{NO}-\mathrm{URB}}=30 \mathrm{ppbvh}^{-1}$ for SUB-1 and $50 \mathrm{ppbv} \mathrm{h}^{-1}$ for URB-1. The chemical term (CHEM) is balanced by EMIS. The deposition term (DEP) is negligible. In both sites, the URBAN TURB term is stronger than the NO-URB one (from $20 \%$ to $60 \%$ ). This stronger turbulence favours the dilution of primary pollutants inside a higher ABL. In fact, the URBAN boundary layer is two or three times higher than the NO-URB one: $206 \mathrm{~m}$ against $72 \mathrm{~m}$
Table 5

\begin{tabular}{|c|c|c|c|c|c|c|}
\hline & Gain/loss & CHEM & TURB & ADV & DEP & EMIS \\
\hline \multicolumn{7}{|c|}{ Urban area $\mathrm{NO}_{2}$ budget } \\
\hline NO-URB & +20.0 & 212.0 & -239.0 & -20.0 & -7.0 & 76.0 \\
\hline URBAN & +0.0 & 189.0 & -253.0 & -9.0 & -2.0 & 76.0 \\
\hline
\end{tabular}

Components of the hourly budget computed for $\mathrm{NO}_{2}$ at daytime, between 1700 and 1800 UTC (Unit ppbvh ${ }^{-1}$ )

at SUB- 1 and $345 \mathrm{~m}$ against $165 \mathrm{~m}$ at URB-1. In this case, the turbulence exports the primary pollutants from the surface and by this process prevents the surface from accumulating $\mathrm{NO}$ as in the NO-URB simulation.

The $\mathrm{O}_{3}$ budget is computed for SUB-1 (Table 4). For this compound, the deposition term is larger, especially for the URBAN case, due to higher ozone concentrations. CHEM and TURB are balanced, the latter term being positive for ozone. The turbulence transfers $\mathrm{O}_{3}$ down from above, while CHEM is a destructive term. TURB is stronger in URBAN than in NO-URB and this term is preponderant for the ozone availability.

In order to conclude this analysis of the effect of the nocturnal urban meteorology on the modelled chemistry, one can note that the situation described here is conditioned by the surface energy exchanges at the origin of the UHI, by the urban boundary layer and its associated turbulence. The latter plays a key role in the spatial distribution of primary and secondary pollutants over the Paris region. As a result, they also drive the compound availability for the diurnal chemistry of the next day. Indeed, several studies have shown that the distribution of ozone fields for a given day strongly determines the ozone spatial distribution of the next day because 
$\mathrm{O}_{3}$ field at $1000 \mathrm{~m}$ (ppbv) on JY16 1700UTC and backtrajectories

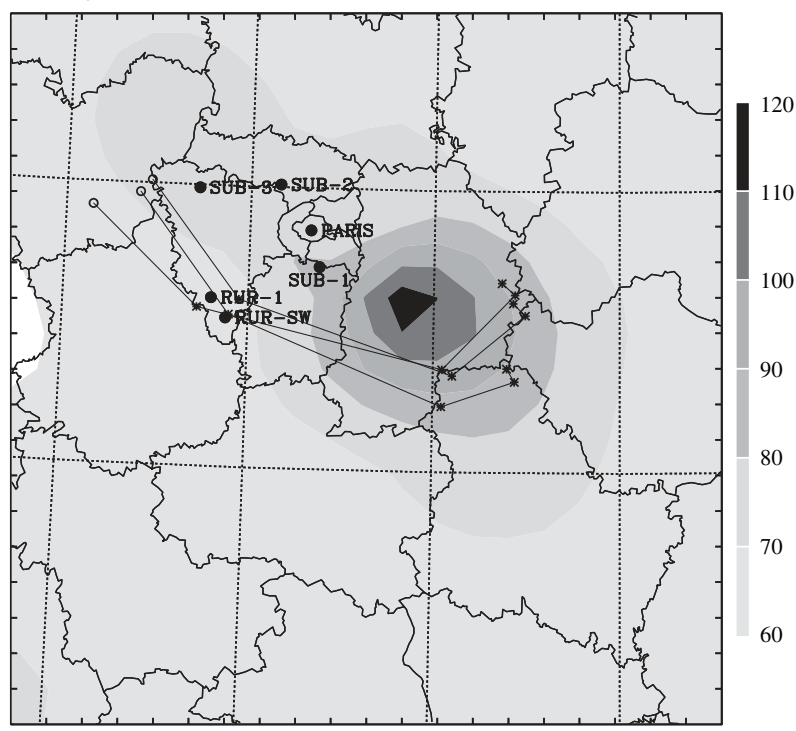

(a)

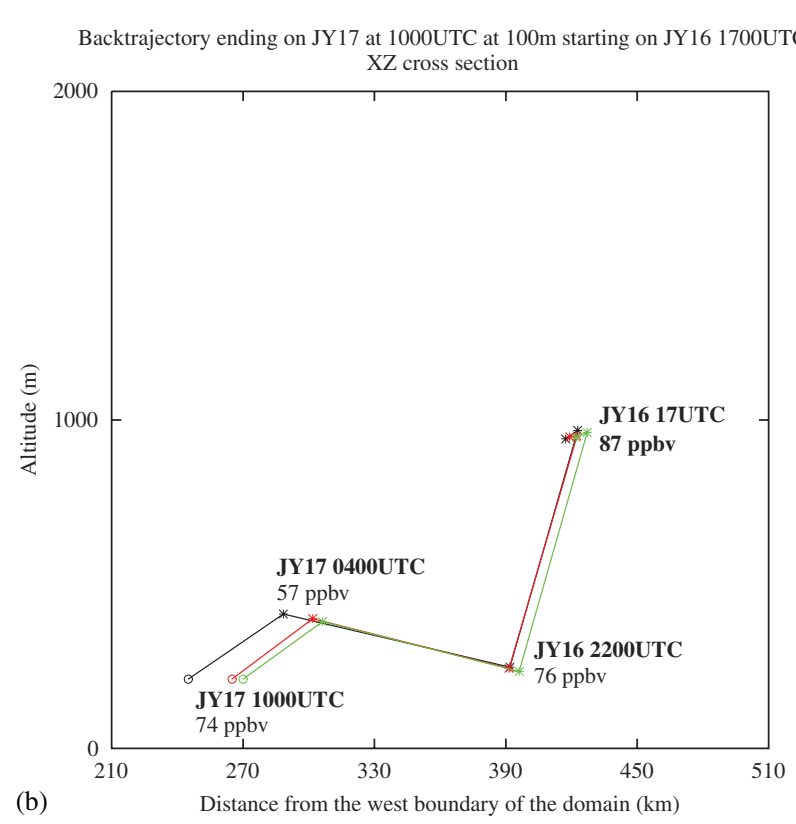

(b)

Fig. 8. (a) Back-trajectories ending on JY17 at 1000 UTC at $100 \mathrm{~m}$ of altitude and starting on JY16 at 1700 UTC superimposed on the ozone simulated field at $1000 \mathrm{~m}$ on JY16 at 1700 UTC. (b) Vertical cross-section and back-trajectories.

the mixing near the surface transports the ozone contained in the residual boundary layer (Neu et al., 1994; Jacobson, 2001). It is quite important to take into account such mechanisms in atmospheric models in order to better understand and represent the origin of regional pollution, as will be shown in the next section.

\subsection{Diurnal effect}

\subsubsection{Availability of pollutants from one day to the} next

The availability of primary and secondary pollutants from one day to the next day is a major uncertainty of atmospheric pollution modelling. Several studies have highlighted the importance of residual ozone in the diurnal development of an ozone episode (Neu et al., 1994). In fact, ozone formed during daytime and contained inside the ABL is destroyed by $\mathrm{NO}_{x}$ near the surface at night, whereas it is still available at higher altitudes inside the residual layer $(\mathrm{RL})$. The next morning when the turbulence increases, the convective boundary layer develops, erodes the RL and mixes the residual ozone near the ground (the coupling of the RL with the ABL was documented during ESQUIF by Fochesatto et al., 2001). Here, on the one hand, the RL is higher and deeper in URBAN than in
NO-URB (1300 and $1100 \mathrm{~m}$ height, respectively). On the other hand, the ozone concentration in RL is higher in URBAN (about 100 ppbv instead 95 ppbv in NO-URB). As a result, the total amount of ozone captured in the RL is larger in URBAN than in NO-URB. The back-trajectory ending on JY17 at 1000 UTC (100 m altitude) back to JY16 at 1700 UTC (illustrated in Fig. 8) clearly evidences the recirculation of the ABL ozone plume $(1000 \mathrm{~m}$ altitude). This ozone remains within the RL during the night and reaches $100 \mathrm{~m}$ on JY17 at 1100 UTC. As the $\mathrm{O}_{3}$ concentrations within the $\mathrm{RL}$ are higher in URBAN than in NO-URB on JY16, the concentrations on JY17 morning are also higher for the URBAN case due to the residual ozone. Moreover, since the URBAN boundary layer is higher than for the NO-URB case at 1100 UTC, the total amount of ozone re-circulated in the URBAN $\mathrm{ABL}$ remains larger.

\subsubsection{Effect of the diurnal UHI}

URBAN also simulates a daytime UHI above the Paris area (Section 4.3 and Fig. 4) associated with a higher ABL ( $2290 \mathrm{~m}$ above Paris instead $1875 \mathrm{~m}$ in NO-URB) and a modification in the wind direction. In both simulations, the distributions of $\mathrm{NO}_{x}$ concentrations are quite different at 1700 UTC according to the horizontal fields at the first 
URBAN SIMUL : NO (ppbv), 07/17/99 17 UTC

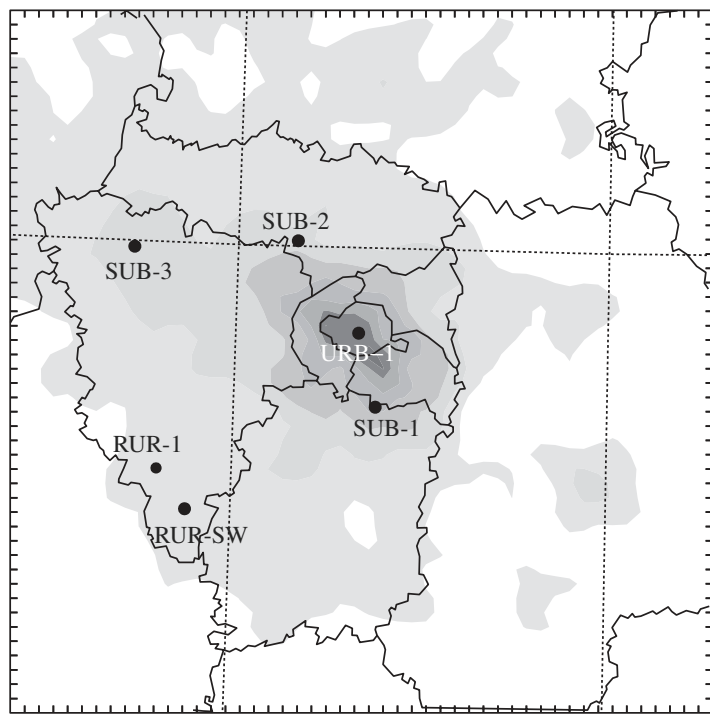

(a)
NO-URB SIMUL : NO (ppbv), 07/17/99 17 UTC

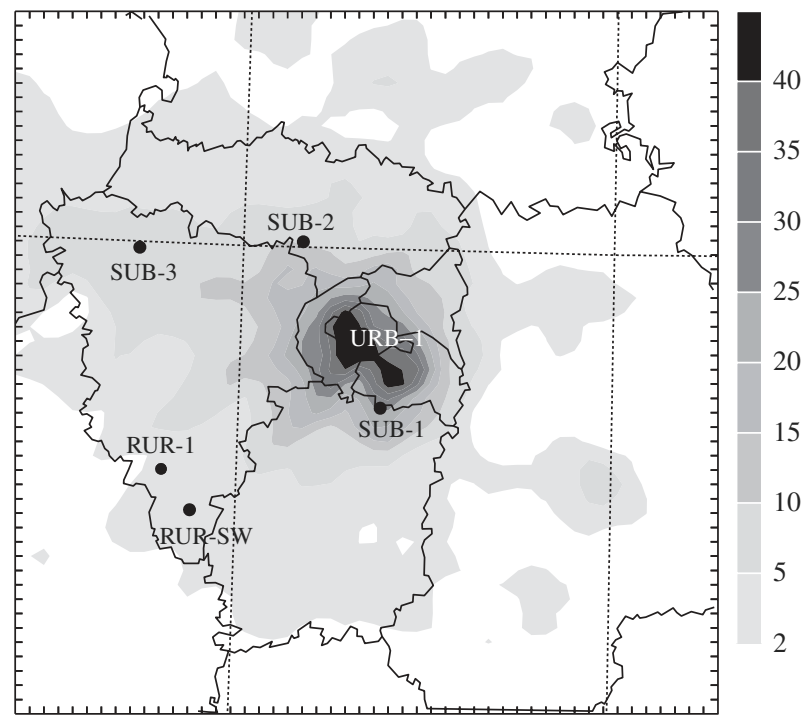

(b)

Fig. 9. Modelled horizontal fields of $\mathrm{NO}_{y}$ concentrations (ppbv) on JY17 at 1700 UTC at $20 \mathrm{~m}$ above the canopy for: (a) URBAN and (b) NO-URB simulations.

atmospheric level presented in Fig. 9: at this level, concentrations are higher in NO-URB than in URBAN over Paris and the suburban area, whereas they are equivalent in the rest of the domain. The previous evaluation against observations also exhibits systematically higher nitrogen oxide concentrations in NO-URB near the surface in Paris (see URB-1 in Fig. 5). NO-URB tends to overestimate $\mathrm{NO}_{x}$ concentrations.

The budget of $\mathrm{NO}_{2}$ (Table 5) is computed for URB-1 between 1700 and 1800 UTC. The evolution of $\mathrm{NO}_{2}$ concentrations remains stable around 23 ppbv for URBAN, while they increase from 33 to $53 \mathrm{ppbv}$ for NO-URB (i.e. $+20 \mathrm{ppbv}$ ). The processes which control pollutant spatial distribution are related to chemistry, i.e. emission and chemical production (according to Eq. 1). The contribution of TURB is stronger in URBAN than in NO-URB. The emphasized turbulence and the vertical mixing are once again due to the urban cover and the air-surface exchanges. As a result, URBAN generates a higher ABL, in which $\mathrm{NO}_{x}$ are more diluted (lower concentrations) for the same anthropogenic emission rate. Such processes seem realistic given the fact that NO-URB simulates overestimated $\mathrm{NO}_{x}$ concentrations.

The spatial distribution of the primary pollutants and thus the $\mathrm{VOC} / \mathrm{NO}_{x}$ ratio (Fig. 10) are affected by the boundary layer height but also by the wind, which changes from one simulation to the other, as seen on the wind field of the Fig. 10: the wind is from the east in NO-URB and is weaker than in URBAN, in which it seems to turn to the north downstream of Paris.

As a consequence, $\left.\left(\mathrm{VOC} / \mathrm{NO}_{x}\right)\right|_{\text {URBAN }}>(\mathrm{VOC} /$ $\left.\mathrm{NO}_{x}\right)\left.\right|_{\text {NO-URB }}$. Yet, this ratio determines the regime of ozone production: ' $\mathrm{NO}_{x}$ sensitive' vs. 'VOC sensitive' according to Sillman (1999). In Paris, in the suburban area and in the plume, the ratio is rather low, i.e. the regime is ' $\mathrm{NO}_{x}$ sensitive', whereas in rural areas the ratio is high and the regime is 'VOC sensitive'. As the ratio is higher for the URBAN simulation, the Paris area, the plume covered zone and all urbanized area in general are the most sensitive to $\mathrm{NO}_{x}$. This sensitivity has to be taken into account for pollution abatement strategy.

\section{Conclusion}

The present paper studies the urban micrometeorology during a summertime anticyclonic episode associated with a high photochemical episode of pollution in the Paris region. It investigates the impact of the urbanized area on the spatial distribution of primary and secondary pollutants above and around the city. Data collected during the IOP6 of ESQUIF campaign allow evaluation of the numerical simulations conducted with the 


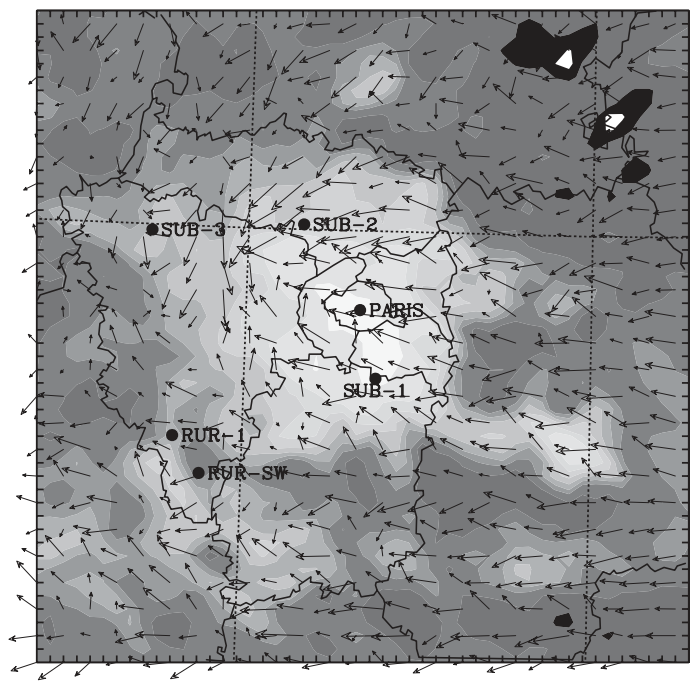

(a)

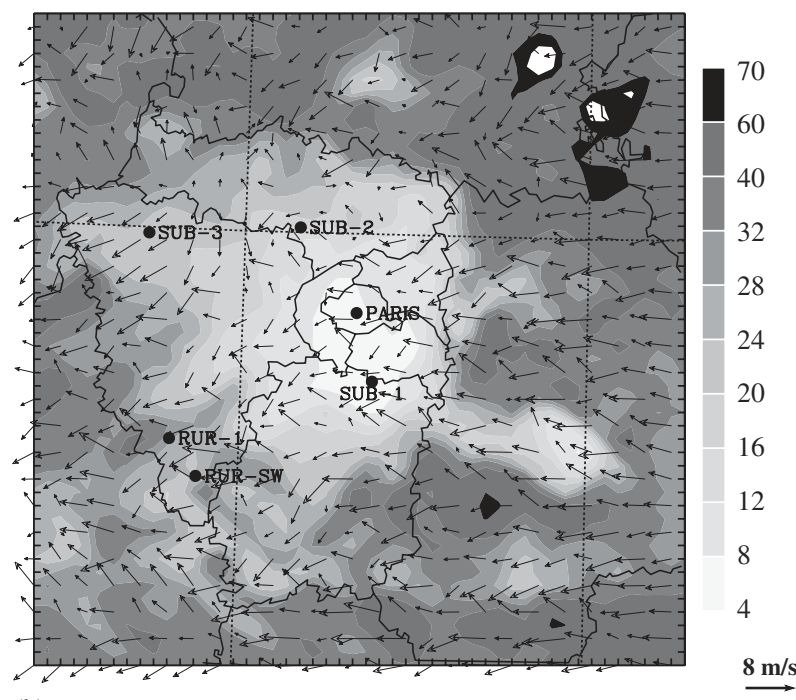

(b)

Fig. 10. Modelled horizontal fields of $\mathrm{VOC} / \mathrm{NO}_{x}$ ratio (ppbvC/ppbv) and wind on JY17 at 1700 UTC at $120 \mathrm{~m}$ above the canopy for: (a) URBAN and (b) NO-URB simulations.

meteorological non-hydrostatic meso-scale model Meso-NHC. In order to quantify the effect of urban areas on both dynamical and chemical processes, a sensitivity study is performed by running the model twice, with (URBAN) and without (NO-URB) the TEB urban surface scheme.

The comparisons between both simulations and the observations and the statistical scores demonstrate that the implementation of the specific urban parameterization in Meso-NHC improves the modelled dynamic parameters such as temperature and humidity, and also the modelled chemical variables such as ozone and $\mathrm{NO}_{x}$ concentrations. The analysis of the model outputs emphasizes that during the night, in agreement with observations the simulation produces an UHI advected by the wind south-west of Paris which induces higher temperatures at this location. During the day, URBAN indicates that the UHI persists over Paris which is also confirmed by the measurements. The strong interactions between chemical and dynamical processes have a very significant impact on the representation of the pollutants at the regional scale.

The computation of $\mathrm{O}_{3}, \mathrm{NO}$ and $\mathrm{NO}_{2}$ budgets in both simulations helps to quantify the effect of each process on the pollutant distribution. In all cases, the turbulent fluxes play a key role compared to the chemistry, the anthropogenic emissions, or the advection. This process drives the spatial distribu- tion of the Paris ozone plume and $\mathrm{NO}_{x}$ concentrations.

\section{References}

Beekmann, M., Derognat, C., 2003. Monte carlo uncertainty analysis of a regional-scale transport chemistry model constrained by measurements from the atmospheric pollution over the Paris area (ESQUIF) campaign. Journal of Geophysical Research 108 (D17).

Blond, N., Bel, L., Vautard, R., 2003. Three-dimensional ozone data analysis with an air quality model over the Paris area. Journal of Geophysical Research 108 (D23).

Bornstein, R., Lin, Q., 2000. Urban heat island and summertime convective thunderstorms in Atlanta: three case studies. Atmospheric Environment 34, 507-516.

Cathala, M., Pailleux, J., Puech, V., 2003. Improving global chemical simulations of the upper troposphere-lower stratosphere with sequential assimilation of mozaic data. Tellus 55 (1).

CEC, 1993. CORINE land cover, technical guide. Technical Report EUR 1285 EN, Office, for the official publications of the European communities, Luxembourg.

Corsmeier, U., Behrendt, R., Drobinski, P., Kottmeier, C., 2005. The mistral and its effect on air pollution transport and vertical mixing. escompte 2001. Atmospheric Research 74, 275-302.

Cousin, F., Tulet, P., Rosset, R., 2005. Interaction between local and regional polluted layers in the low troposphere: impact on surface concentrations during escompte 2001. Atmospheric Research 74, 117-137.

Crassier, V., Suhre, K., Tulet, P., Rosset, R., 2000. Development of a reduced chemical scheme for use in mesoscale meteorological models. Atmospheric Environment 34, 2633-2644. 
Cros, B., Durand, P., Frejafon, E., Kottmeier, C., Perros, P., Peuch, V., Ponche, J., Robin, D., Sad, F., Toupance, G., Wortham, H., 2004. The ESCOMPTE program: an overview. Atmospheric Research 69 (3-4), 241-279.

Crutzen, P., 2004. New directions: the growing urban heat and pollution 'island' effect-impact on chemistry and climate. Atmospheric Environment 38, 3539-3540.

Derognat, C., Beekman, M., Baeumle, M., Martin, D., Schmidt, H., 2003. Effect of biogenic VOC emissions on the tropospheric chemistry during elevated ozone periods in Ile-deFrance. Journal of Geophysical Research 108 (D17).

Dupont, E., Menut, L., Carissimo, B., Pelon, J., Flamant, P., 1999. Comparison between the atmospheric boundary layer in Paris and its rural suburbs during the ECLAP experiment. Atmospheric Environment 33, 979-994.

Escourrou, G., 1991. Le climat et la ville. Revue Geographique de Lyon, Nathan.

Estournel, C., Vehil, R., Guedalia, D., Fontan, J., Druilhet, A., 1983. Observations and modeling of downward radiative flux (solar and infrared) in urban/rural areas. Journal of Applied Meteorology 22, 134-142.

Fochesatto, X., Drobinski, P., Flamant, C., Guedalia, D., Sarrat, C., Flamant, P., Pelon, J., 2001. Evidence of dynamical coupling between the residual layer and the developing boundary layer. Boundary-Layer Meteorology 99 (3), 451-464.

Guenther, A., Zimmerman, P., Harley, P., Monson, R., Fall, R., 1993. Isoprene and monoterpene emission rate variability: model evaluations and sensitivity analyzes. Journal of Geophysical Research 98 (D7), 12609-12617.

Henne, S., Furger, M., Nyeki, S., Steinbacher, M., Neininger, B., de Wekker, S., Dommen, J., Spichtinger, N., Stohl, A., Prévôt, A., 2003. Quantification of tropographic venting of the boundary layer air to the free troposphere. Atmospheric Chemistry and Physics Discussions 3, 5205-5236.

Jacobson, M., 2001. GATOR-GCMM. 2. A study of daytime and nightime ozone layers aloft, ozone in national parks, and weather during the SARMAP field campaign. Journal of Geophysical Research 106 (D6), 5403-5420.

Kambezidis, H.D., Peppes, A.A., Melas, D., 1995. An environmental experiment over Athens urban area under sea breeze conditions. Atmospheric Research 36, 139-156.

Lafore, J., Stein, J., Bougeault, P., Ducrocq, V., Duron, J., Fischer, C., Héreil, P., Marcart, P., Masson, V., Pinty, J.-P., Redelsperger, J., Richard, E., de Arellano, J.V., 1998. The Meso-NH atmospheric simulation system. Part I: adiabatic formulation and control simulations. Annales Geophysicae 16, 90-109.

Lemonsu, A., Masson, V., 2002. Simulation of summer urban breeze over Paris. Boundary-Layer Meteorology 104, 463-490.

Lemonsu, A., Pigeon, G., Masson, V., Durand, P., Moppert, C., 2005. Sea-town interactions over marseille: $3 \mathrm{~d}$ urban boundary layer structure and thermodynamical fields near the surface. Theoretical Applied Climatology 10.1007/s00704005-0155-y.

Martilli, A., Roulet, Y., Junier, M., Kirchner, F., Rotach, M., Clappier, A., 2003. On the impact of urban surface exchange parameterizations on air quality simulations: the Athens case. Atmospheric Environment 37, 4217-4231.

Masson, V., 2000. A physically based scheme for the urban energy budget in atmospheric models. Boundary-Layer Meteorology 94, 357-397.
Menut, L., 2003. Adjoint modeling for atmospheric pollution process sensitivity at regional scale. Journal of Geophysical Research 108 (D17).

Menut, L., Vautard, R., Flamant, C., Abonnel, C., Beekmann, M., Chazette, P., Flamant, P.H., Gombert, D., Guedalia, D., Kley, D., Lefebvre, M., Lossec, B., Martin, D., Megie, G., Sicard, M., Perros, P., Toupance, G., 2000. Measurement and modeling of atmospheric pollution over the Paris area: the ESQUIF Project. Annales Geophysicae 18 (11), 1467-1481.

Neu, U., Knzle, T., Wanner, H., 1994. On the relation between ozone storage in the residual layer and daily variation in nearsurface ozone concentration - a case study. Boundary-Layer Meteorology 69, 221-247.

Noilhan, J., Planton, S., 1989. A simple parametrization of land surface processes for meteorological models. Monthly Weather Review 117, 536-549.

Nunez, R., Oke, T., 1977. The energy balance of urban canyon. Journal of Applied Meteorology 16, 11-199.

Oke, T.R., 1982. The energic basis of the Urban Heat Island. Quarterly Journal of the Royal Meteorological Society 108, $1-24$.

Oke, T.R., 1987. Boundary Layer Climates. Methen, London, second ed. 435pp.

Oke, T.R., East, C., 1971. The urban boundary layer in Montréal. Boundary-Layer Meteorology 1, 411-437.

Oke, T.R., Spronken-Smith, R., Jáuregui, E., Grimmond, C., 1999. The energy balance of central Mexico city during the dry season. Atmospheric Environment 33, 3919-3930.

Puech, V., Amodei, M., 1999. MOCAGE: MOdèle de Chimie Atmosphérique à Grande Echelle. Compte-rendus des A.M.A., Centre Nationale de recherches Météorologiques, Toulouse.

Schmidt, H., Martin, D., 2003. Adjoint sensitivity of episodic ozone in the Paris area to emissions on the continental scale. Journal of Geophysical Research 108 (D17).

Sillman, S., 1999. The relation between ozone, $\mathrm{NO}_{x}$ and hydrocarbons in urban and polluted rural environments. Atmospheric Environment 33, 1821-1845.

Sillman, S., Vautard, R., Menut, L., Kley, D., 2003. $\mathrm{O}_{3}-\mathrm{NO}_{x-}$ VOC sensitivity and $\mathrm{NO}_{x}-\mathrm{VOC}$ indicators in Paris: results from models and atmospheric pollution over the Paris area (ESQUIF) measurements. Journal of Geophysical Research 108 (D12).

Solmon, F., Sarrat, C., Serça, D., Tulet, P., Rosset, R., 2004. Modeling isoprene and monoterpenes biogenic emission in France: impact study during a regional pollution episode. Atmospheric Environment 38 (28), 3853-3865.

Stockwell, W., Kirchner, F., Kuhn, M., Seefeld, S., 1997. A new mechanism for regional atmospheric chemistry modeling. Journal of Geophysical Research 102 (D22), 25847-25880.

Suhre, K., Mari, C., Bares, T., Johnson, J., Rosset, R., Wang, Q., Bandy, A., Blake, D., Businger, S., Eisels, F., Huebert, B., Kok, G., Mauldin, R., Prévôt, A., Schillawski, R., Tanner, D., Thornton, D., 1998. Physico-chemical modeling of the first aerosol characterization experiment (ACE 1) Lagrangian B,1. A moving column approach. Journal of Geophysical Research 103, 16433-16455.

Troude, F., Dupont, E., Carissimo, B., Flossmann, A., 2002. Relative influence of urban and orographic effects for low wind conditions in Paris area. Boundary-Layer Meteorology 103, 493-505. 
Tulet, P., Maalej, A., Crassier, V., Rosset, R., 1999. An episode of photooxidant plume pollution over the Paris region. Atmospheric Environment 33, 1651-1662.

Vautard, R., Martin, D., Beekmann, M., Drobinski, P., Friedrich, R., Jaubertie, A., Kley, D., Lattuati, M., Neininger, P.M.B., Theloke, J., 2003a. Paris emission inventory diagnostics from ESQUIF airborne measurements and a chemistry transport model. Journal of Geophysical Research 108 (D17).

Vautard, R., Menut, L., Beekmann, M., Chazette, P., Flamant, P., Gombert, D., Guedalia, D., Kley, D., Lefebvre, M.,
Martin, D., Megie, G., Perros, P., Toupance, G., 2003b. A synthesis of the air pollution over the Paris region (ESQUIF) field campaign. Journal of Geophysical Research 108 (D17).

Wesely, M., 1989. Parameterization of surface resistances to gaseous dry deposition in regional scale numerical models. Atmospheric Environment 23 (1), 1293-1304.

Wickert, B., Schwarz, U., Blank, P., John, C., Khlwein, J., Obermier, A., Friedrich, R., 1999. Generation of an emission data base for Europe 1994. Proceedings of EUROTRAC Symposium R98 2, 255-265. 